\title{
Trends in performance of science and technology students (1997-2008) in Ireland
}

\author{
Fiona Faulkner \\ Technological University Dublin, fiona.faulkner@tudublin.ie \\ Olivia Gill \\ University of Limerick \\ Ailish Hannigan \\ University of Limerick
}

Follow this and additional works at: https://arrow.tudublin.ie/ltcart

Part of the Education Commons

\section{Recommended Citation}

Faulkner, F., Hannigan, A. \& Gill, O. (2010). Trends in performance of science and technology students (1997-2008) in Ireland. International Journal of Mathematical Education in Science and Technology, vol. 41, no. 3, pp. 323-339. doi:10.1080/00207390903477426

This Article is brought to you for free and open access by the Learning Teaching \& Assessment at ARROW@TU Dublin. It has been accepted for inclusion in Articles by an authorized administrator of ARROW@TU Dublin. For more information, please contact arrow.admin@tudublin.ie, aisling.coyne@tudublin.ie, gerard.connolly@tudublin.ie.

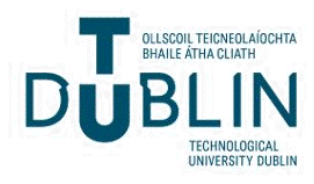




\title{
Trends in performance of science and technology students (1997-2008) in Ireland
}

\author{
Olivia Gill*, John O’Donoghue, Fiona Faulkner and Ailish Hannigan \\ Department of Mathematics and Statistics, University of Limerick, Limerick, Ireland
}

(Received 2 July 2009)

\begin{abstract}
Hunt and Lawson [1] displayed the evidence of decline in the mathematical standards of first-year students in Coventry University between 1991 and 1995. Gill [2] sought to investigate if this was also the case in the University of Limerick. The results of diagnostic tests administered to first-year undergraduates in the science and technology groups (service mathematics courses) between 1997 and 2002 displayed the evidence that the mathematical standard of students entering the University of Limerick's service mathematics courses had declined over the 6 years studied. In this article, the authors revisit the University of Limerick's database, which currently holds data for over 6200 students, to investigate current mathematical entry standards of students in service mathematics courses. The University of Limerick's responses to the 'Mathematics Problem' are also described. Ireland presents a unique situation in terms of the mathematical homogeneity of its third-level students; most students enter via the same route, i.e. the Leaving Certificate, on completion of 13 years of formal mathematics education. However, while research results and coping mechanisms in terms of learning support are not generalizable, they are portable. It is hoped that mathematics educators worldwide can learn from the Irish situation.
\end{abstract}

Keywords: mathematics problem; database; diagnostic testing; mathematics learning centre

\section{Background to study}

The 'Mathematics Problem' has generated much discussion and unease internationally the mathematics education community for the past 20 years [3-10]. The issue of mathematical preparedness is a significant concern worldwide because developed countries, e.g. UK, Australia, USA, Ireland, base future economic development on a knowledge society which values scientific, technological and mathematical skills very highly $[7,9,10]$. The issue is no less important for Ireland where economic development is closely articulated with third-level education. Repeated studies have signalled the importance of mathematics for the economy $[3,11]$.

O'Donoghue [11] presented some of the first empirical evidence of the existence and extent of the 'Mathematics problem' in Ireland. A pilot study, by means of diagnostic testing, was undertaken in 1997/98 to determine the existence, nature and extent of the 'Mathematics Problem' in first-year service mathematics courses in the

*Corresponding author. Email: olivia.gill@ul.ie 
University of Limerick (UL). A total of 257 (out of 308) technology mathematics students (one of the largest service mathematics groups in UL) sat for a 40-question diagnostic test (see Appendix 1 for sample) in the third week of the first semester. Of this, $20(50 \%)$ questions were selected as the benchmark that determined whether the students were 'at risk' or not. The term 'at-risk' is used in two senses in this article. It is the term used in a general sense when the authors talk about entering students who are likely to fail their mathematics modules because they are mathematically underprepared by their school mathematics experience. More specifically, they are the first-year students who have been identified by their performance in the UL diagnostic test scoring less than 20 marks out of 40. They are classified as 'at-risk' as they are either at risk of having difficulties keeping up with the pace of their mathematics classes, at risk of failing their mathematics modules and not proceeding to the next year of their degree programmes, or at risk of dropping out of the university system because of failing mathematics. The benchmark of 20 out of 40 was due in part to the level of the test and also the desire to identify only those who were really going to need extra support to successfully complete their first-year service mathematics modules. There were $69(27 \%)$ students in this category [11].

The study was important, in that not only did it provide concrete evidence of mathematical underpreparedness in first-year service mathematics cohorts, in addition it also identified many issues that fed this problem (e.g. government policy of mass higher education, the Irish Leaving Certificate Points system, etc.). Furthermore, it helped establish the provision of a number of learning support services including the development of a mathematics learning centre (MLC) - the first in Ireland. In addition, a database of diagnostic test and end-of-semester results were instigated in line with the pilot study in 1997 and has been updated by the authors annually since. The database currently contains records on 6206 students.

\subsection{Rationale}

Murphy [12], in her research on the transition from secondary school mathematics to university mathematics in Ireland, recognized the need for caution in interpreting the nature of the 'Mathematics Problem' in Ireland. While there were undoubted similarities across countries, local conditions, practices and needs contribute to different manifestations of the problem in different countries. It is necessary, therefore, for researchers to examine and understand the 'Mathematics Problem' as it exists in their own country so that they tackle their own problem. The experience of other countries can be relied on for insights and guidance, but the problem will not be replicated exactly in any other country and even if it were, the solutions would not transfer directly without adaptation.

In this article, the authors use the University of Limerick's database, compiled at the MLC for the purpose of obtaining definitive evidence on the 'Mathematics Problem' in Ireland to map the aspects of the 'Mathematics Problem' at system level. The database is unique in Ireland and constitutes a valuable resource for researchers interested in this area. Gill [2] carried out a preliminary analysis of the database (1997-2003) as part of her doctoral studies. This research represented the first major attempt to 'localise' the 'Mathematics Problem' for an Irish university. Currently, the database contains data for 11 years, so further analysis is warranted. 
The authors are guided in this analysis by a number of research questions. They include:

- Is there a 'Mathematics Problem' in UL regarding service mathematics courses?

- How many entering first-year students in UL service mathematics courses are 'at risk'?

- Has there been a decline in the mathematical standards of students entering first-year service mathematics courses in UL?

This approach allows the authors to develop a better understanding of the 'Mathematics Problem' and gain a better understanding of Ireland's response in the wider context of good international practice. It further allows the authors to identify the similarities and differences between Ireland and other countries and to chart new directions for Ireland based on a better understanding of the 'Mathematics Problem' over an extended time frame.

\subsection{Methodology}

Longitudinal studies are, by definition, carried out over an extended period of time and the data attained are generally taken from the same cohort. In this study, the data collected and analysed were collected over several years but the cohorts changed from year to year. However, the same diagnostic test had been used from year to year, so comparative statistical analysis could be carried. This helped ensure a high level of reliability. Validity was ensured as the measurement instrument, the diagnostic test (Appendix 1) was designed carefully to suit the mathematical level and disciplines of the respondents to be targeted. A provisional set of 70 questions was given to a panel of lecturers who had extensive experience in the field of service mathematics teaching. The list of questions was refined to the 40 deemed most suitable for the test. The test was piloted in secondary schools and checked against the SEFI Core Level Zero syllabus for engineers [13], the Irish Junior Certificate mathematics syllabus, the Irish Leaving Certificate ordinary level mathematics syllabus and other diagnostic tests.

Gill [2] carried out statistical analysis on the first 6 years of the UL database, i.e. $1997 / 98,1998 / 99,1999 / 2000,2000 / 01,2001 / 02$ and 2002/03. At this stage, there were 2121 students in the database. Currently, the database contains data for 11 years for 6209 students. The statistical software package SPSS was used to analyse the database.

\subsection{The mathematical background of Irish students}

Irish third-level students, in general, are much more homogeneous in terms of mathematical background compared to their international counterparts for two main reasons. First, the majority of Irish students study mathematics for at least 13 years prior to proceeding to third-level education. Second, access to third level is attained via the Leaving Certificate, of which mathematics is a compulsory component. Most subjects are assessed at two levels (higher and ordinary) while English, Irish and mathematics are assessed at three levels (higher, ordinary and foundation). Points are awarded according to level of participation and grade awarded. This 'Points' system, based on six subjects, determines entry to and allocation of third-level courses (Table 1). 
Table 1. Leaving Certificate points system.

\begin{tabular}{lccc}
\hline Grade & Points & Grade & Points \\
\hline HA1 & 100 & OA1 & 60 \\
HA2 & 90 & OA2 & 50 \\
HB1 & 85 & OB1 & 45 \\
HB2 & 80 & OB2 & 40 \\
HB3 & 75 & OB3 & 35 \\
HC1 & 70 & OC1 & 30 \\
HC2 & 65 & OC2 & 25 \\
HC3 & 60 & OC3 & 20 \\
HD1 & 55 & OD1 & 15 \\
HD2 & 50 & OD2 & 10 \\
HD3 & 45 & OD3 & 5 \\
\hline
\end{tabular}

Note: HA1, grade A1 in higher level; OB1, grade B1 in ordinary level.

Approximately 12,000 (2000 part-time) students are registered in UL and up to $90 \%$ of these students would study mathematics at some point during their degree programmes.

\subsection{The UL diagnostic test}

The UL diagnostic test is a paper-based test comprising 40 open-ended questions with a single correct response. The test (Appendix 1) is divided into nine sections: arithmetic (13 questions), algebra (eight questions), geometry (four questions), trigonometry (three questions), coordinate geometry (four questions), complex numbers (two questions), differentiation (three questions), integration (two questions) and modelling (one question). The test was designed for marking by hand so that one could investigate the specific errors that students make and identify where the gaps in student knowledge lie. Thirty-five out of the 40 questions on the test are pitched at Leaving Certificate ordinary level or below.

\section{The UL database}

In this section, the authors give a more detailed profile of the UL database and of the groups of students involved.

The UL database was initiated in the academic year 1997/98 and has been maintained up to and including the present year. It contains data for two of the largest service mathematics groups in UL, science and technology students. At the time, it was feared that falling standards in mathematics within science and technology courses would diminish standards of degree qualifications and, long term, affect the country's economic performance adversely. Therefore, the pilot study by O'Donoghue [11] was a response to address a national priority in terms of improving throughput and quality in science and technology degrees. As a result, the diagnostic test was designed with an engineering/technology bias and these specific groups were targeted [11]. In the first year of testing (1997/98), only the technology students were tested, so for that year there is no data on the science students, so the data for this particular year is eliminated from the analysis in Section 3. 
Table 2. Numbers of students in database by group.

\begin{tabular}{|c|c|c|c|c|c|c|c|c|c|c|c|c|c|}
\hline \multirow[b]{2}{*}{ Group } & \multicolumn{13}{|c|}{ Year } \\
\hline & 1997 & 1998 & 1999 & 2000 & 2001 & 2002 & 2003 & 2004 & 2005 & 2006 & 2007 & 2008 & Total \\
\hline Science & 0 & 202 & 209 & 219 & 157 & 172 & 205 & 239 & 255 & 285 & 284 & 303 & 2530 \\
\hline $\begin{array}{l}\text { Within } \\
\quad \text { year }(\%)\end{array}$ & 0 & 40 & 40 & 38 & 35 & 43 & 48 & 50 & 45 & 42 & 42 & 45 & 41 \\
\hline Technology & 257 & 305 & 311 & 352 & 286 & 229 & 222 & 244 & 312 & 390 & 394 & 374 & 3676 \\
\hline $\begin{array}{l}\text { Within } \\
\quad \text { year }(\%)\end{array}$ & 100 & 60 & 60 & 62 & 65 & 57 & 52 & 50 & 55 & 58 & 58 & 55 & 59 \\
\hline
\end{tabular}

For each student, there are over 60 items of information. For confidentiality purposes, the students' UL identification numbers are used instead of their names. Added to this, there are entries for the year they started in UL, their end-of-term grades (percentages) for semesters 1 and 2, the number of times they attended support tutorials (if any) in both semesters, their gender, Leaving Certificate level and grade, the programme of study they are pursuing in UL, their diagnostic test score total (out of 40) and their test profiles based on questions 1-40 (correct or incorrect/unanswered). Each student has a score total entered for each of the nine categories, i.e. arithmetic, algebra, etc.

At present, there are 6206 students recorded in the database over 11 years from $1997 / 98$ to 2008/09. Table 2 displays the number of students per group (i.e. technology and science students) in the database.

There are more students in the technology mathematics 1 cohort than in science mathematics 1 with participation levels in both groups increasing by up to $50 \%$ over the 12 years (from 202 in science mathematics 1 in 1998 to 303 in 2008 and from 257 in technology mathematics 1 in 1997 to 374 in 2008) due in part to the increased number of degree programmes on offer in UL; from 8 to 14 degree programmes in technology and from 8 to 11 in science mathematics (see Table 3 for degree programmes on offer in 2008).

\subsection{Leaving Certificate levels}

Table 4 outlines the mathematical background of students entering science and technology mathematics courses over the 12-year period ('Other or Missing' refers to non-standard students with international qualifications, students who have no Leaving Certificate within the last 10 years or at all).

Science mathematics 1 is mathematically more difficult than technology mathematics 1 . The minimum entry requirement for science mathematics 1 is an ordinary level B3 at Leaving Certificate (from 70 to $<75 \%$ ) or equivalent. For technology mathematics, this entry requirement is set at a $\mathrm{C} 3$ at ordinary level (from 55 to $<60 \%$ ) or equivalent.

While in 1998, the mathematical background of science mathematics 1 students was superior in general to those in technology mathematics 1, in 2008 it was less so. Initially, science mathematics 1 had a higher number of students with higher level Leaving Certificate mathematics $(55.4 \%$ in 1998). This figure decreased quite significantly to $38 \%$ in 2008 . In line with this decrease, the number of non-standard 
Table 3. Degree programmes within technology and science 2008.

Science degree programmes 2008

Technology degree programmes 2008

- Biological science

- Biomedical and advanced materials

- Environmental science

- Food science and health

- Health and safety

- Industrial biochemistry

- Joint honours

- Law plus

- Pharmaceutical and industrial chemistry

- Physical sciences

- Sport and exercise science
- Applied computing and network technologies

- Production management

- Construction management and engineering

- Materials and construction technology

- Computer systems

- Digital media design

- Electronic systems

- Engineering science (with minor option)

- Manufacturing systems

- Multimedia and computer games development

- Physical education

- Wood science and technology

- Product design and technology

- Music, media and performance technology

Table 4. Leaving Certificate level of students in database.

\begin{tabular}{|c|c|c|c|c|c|c|c|c|c|c|c|c|c|c|}
\hline Group & Level & 1997 & 1998 & 1999 & 2000 & 2001 & 2002 & 2003 & 2004 & 2005 & 2006 & 2007 & 2008 & Total \\
\hline \multirow[t]{3}{*}{ Science } & $\begin{array}{l}\text { Higher } \\
\quad \text { level }(\%)\end{array}$ & & 55 & 66 & 48 & 53 & 49 & 45 & 46 & 44 & 36 & 36 & 38 & 46 \\
\hline & $\begin{array}{l}\text { Ordinary } \\
\quad \text { level }(\%)\end{array}$ & & 43 & 33 & 51 & 44 & 48 & 44 & 46 & 51 & 54 & 59 & 55 & 49 \\
\hline & Other $(\%)$ & & 2 & 1 & 1 & 3 & 3 & 10 & 8 & 5 & 10 & $J$ & 7 & 5 \\
\hline \multirow[t]{3}{*}{ Technology } & $\begin{array}{l}\text { Higher } \\
\quad \text { level }(\%)\end{array}$ & 41 & 41 & 40 & 40 & 35 & 39 & 34 & 37 & 35 & 32 & 38 & 33 & 37 \\
\hline & $\begin{array}{l}\text { Ordinary } \\
\quad \text { level }(\%)\end{array}$ & 59 & 59 & 53 & 57 & 62 & 59 & 63 & 57 & 61 & 55 & 56 & 58 & 58 \\
\hline & Other $(\%)$ & 0 & 0 & 7 & 3 & $3 \%$ & 2 & 3 & 6 & 4 & 13 & 6 & 9 & 5 \\
\hline
\end{tabular}

students has increased from $1.5 \%$ in 1998 to $7.3 \%$ in 2008. (This particular phenomenon is being researched by the authors currently and will be reported fully at a future time.)

For technology mathematics 1 , the decrease in the percentage of students with higher level Leaving Certificate mathematics has not been so dramatic $(40.9 \%$ in 1997 to $33.2 \%$ in 2008). The number of students with ordinary level Leaving Certificate mathematics has remained fairly consistent over the 12-year span. What is interesting here is the rise from $0 \%$ (in 1997) to $9.4 \%$ (in 2008) of non-standard or missing students.

\subsection{Gender}

There has been a shift in the gender balance within the science cohort whereas in the technology groups, it has remained consistent. At the start of the study in 1998, $63.4 \%$ of the students in science were female. This bias, in favour of females, would 
have been due to a number of factors including the emphasis on biological sciences within the college of science and the large number of females in the science education programmes. In the ensuing year, this female/male ratio changed to 56.5 and $43.5 \%$, respectively. This remained pretty consistent until 2008, where a $53.1 \%$ male participation was evidenced, possibly due to the addition of courses such as health and safety and physical science where male participation rates are higher. In 1997, $85 \%$ on the technology group were male rising to only $86 \%$ in 2008 .

\section{Trends in performance 1998-2008}

The authors target what they style as system level issues in this phase of the analysis which proceeds as follows:

- Numbers of at-risk students in the database.

- Trends in performance on the diagnostic test.

\subsection{Numbers of at-risk students in the UL database}

A student is categorized as 'at-risk' if they score below 20 out of 40 in the diagnostic test. Figure 1 displays how the percentage of at-risk students in the database has increased since 1998. (Data for 1997 is omitted from this stage of analysis as there is no data for science mathematics 1 students in this year.)

Table 5 highlights the evidence of an increase in the number of potentially at-risk students within both science and technology mathematics.

The figures given in the table clearly display the evidence of an increase in the number of at-risk students within both science and technology mathematics. In fact, the percentages have more than doubled in science mathematics since diagnostic testing first began. In 1998, 21.3\% of this cohort was diagnosed as being at risk. In $2008,46 \%$ of this cohort was at risk (Figure 2).

For technology mathematics, the same worrying trend is apparent though not as dramatic. In 1998, 32.8\% of this particular group were in the at-risk group. This rose to $46.4 \%$ by 2008 (Figure 3).

\subsection{Trends in performance on the $U L$ diagnostic test}

The authors intend to provide empirical evidence of a suspected decline in mathematical standards on entry to these courses as measured by the UL diagnostic test. This decline in standards will be investigated under the following subheadings:

- Service mathematics courses

- Leaving Certificate mathematics levels

Independent sample's $t$-tests are carried out to investigate if there was a significant difference between the means of each category between the years 1998 and 2008. A significance level of 5\% was used for all tests and no adjustment was made to multiple testing. The results of this analysis are outlined below.

\subsubsection{Service mathematics courses}

Figure 4 exhibits the mean diagnostic scores for both technology mathematics and science mathematics students between 1998 and 2008. 


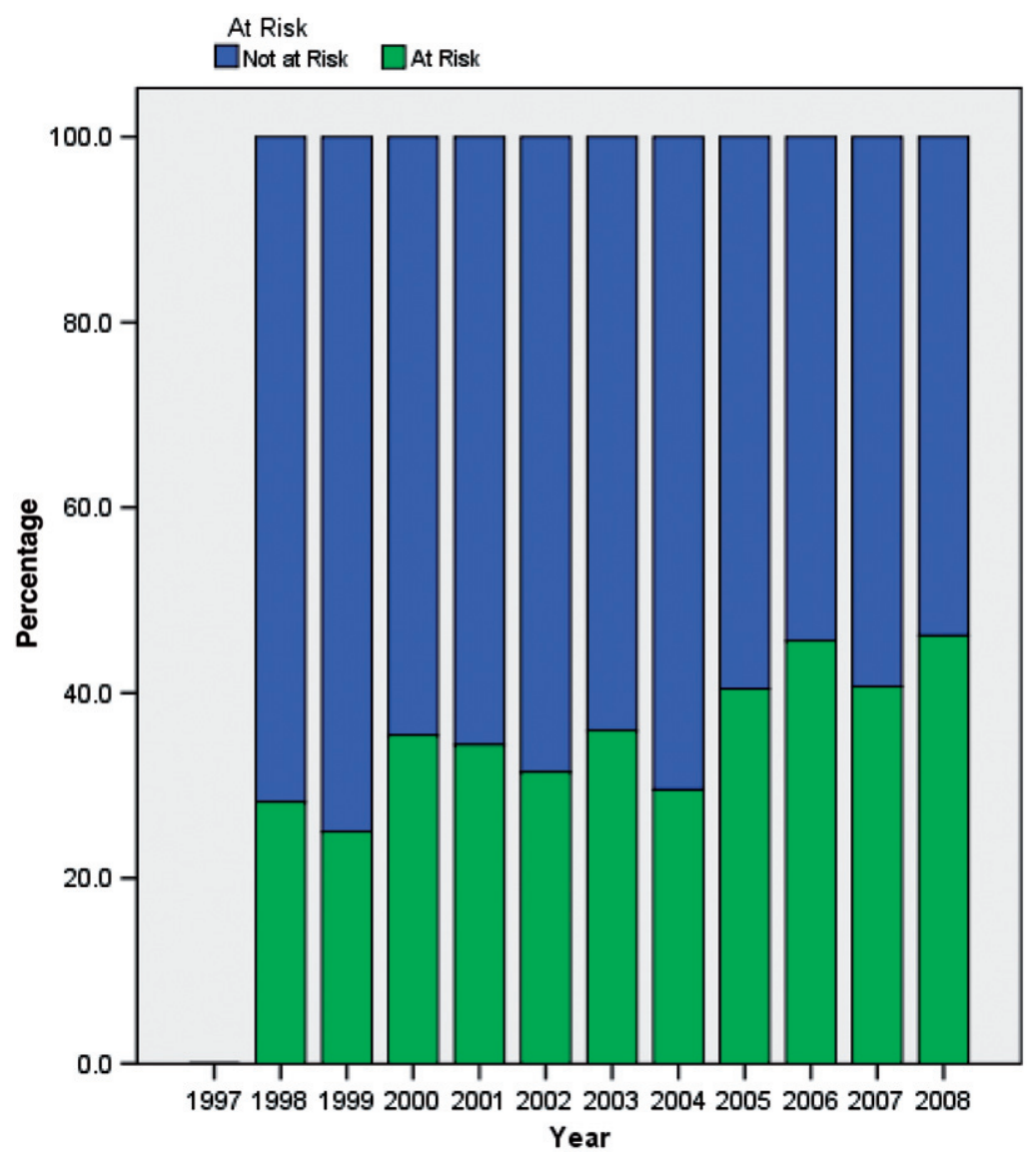

Figure 1. Percentage of at-risk students in database.

Table 5. Numbers of potentially at-risk students in database.

\begin{tabular}{|c|c|c|c|c|c|c|c|c|c|c|c|c|}
\hline Group & 1998 & 1999 & 2000 & 2001 & 2002 & 2003 & 2004 & 2005 & 2006 & 2007 & 2008 & Total \\
\hline $\begin{array}{l}\text { Potential } \\
\text { at-risk } \\
\text { students } \\
\text { in science }\end{array}$ & 43 & 38 & 58 & 38 & 36 & 40 & 40 & 80 & 131 & 124 & 109 & 737 \\
\hline Percentage & 21.3 & 20.1 & 30.1 & 28.1 & 25.5 & 26.7 & 22.1 & 35.2 & 49.2 & 47.1 & 46.0 & 33.7 \\
\hline $\begin{array}{l}\text { Potential } \\
\text { at-risk } \\
\text { students in } \\
\text { technology }\end{array}$ & 100 & 76 & 118 & 81 & 75 & 81 & 80 & 121 & 154 & 112 & 140 & 1190 \\
\hline Percentage & 32.8 & 28.5 & 38.8 & 38.4 & 35.4 & 43.3 & 35.6 & 44.8 & 42.9 & 35.3 & 46.4 & 37.0 \\
\hline
\end{tabular}

A downward trend is evident for both cohorts of students. Looking at the science mathematics students' mean diagnostic test scores, there is a difference of 5 between $1998(M=25.2, \mathrm{SD}=6.54)$ and $2008(M=20.2, \mathrm{SD}=7.15)$. The difference between the means is statistically significant $(t(441)=7.67, p<0.001)$ and the standard 


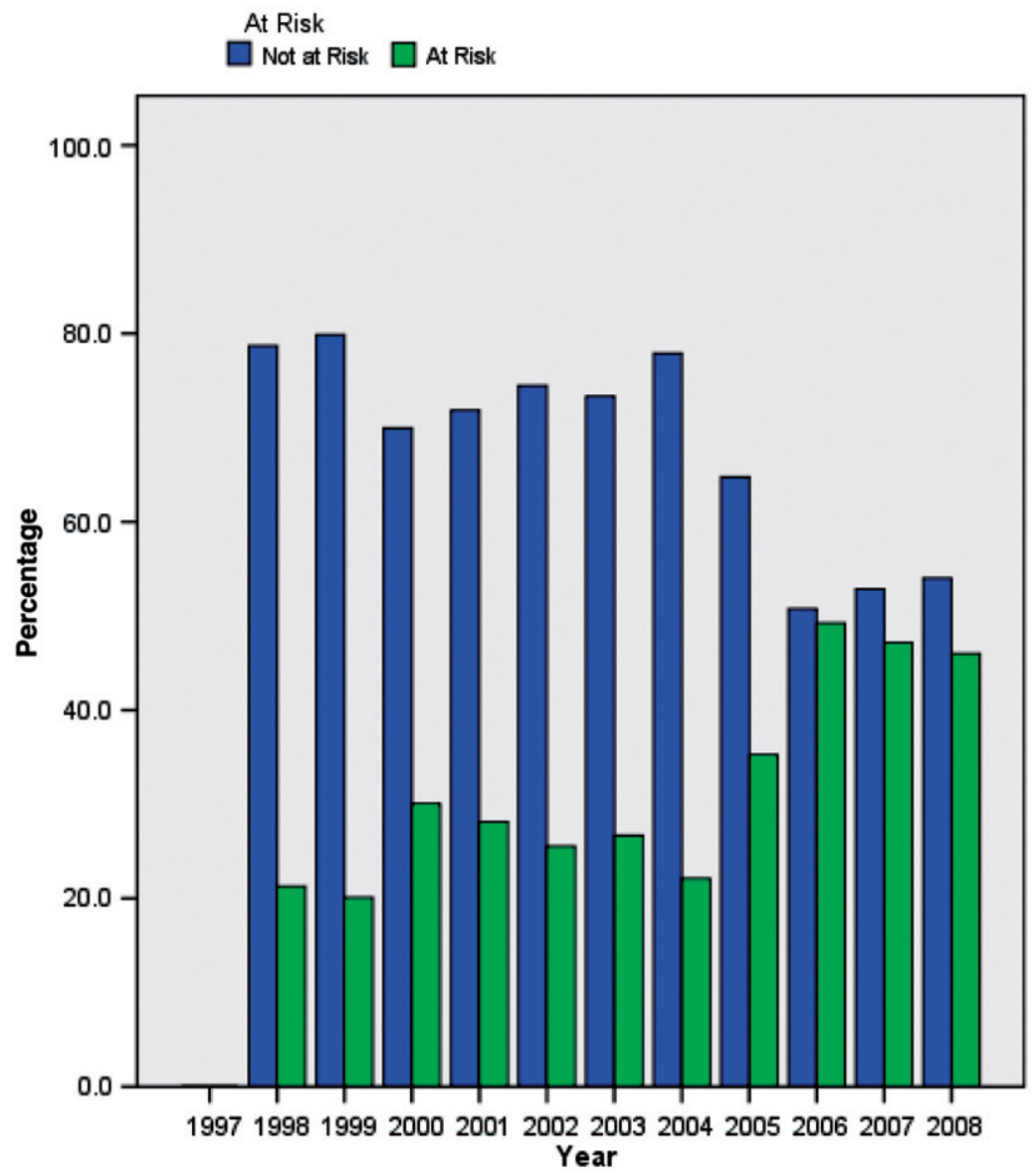

Figure 2. Number of at-risk students in science mathematics.

deviations indicate that not only is the mean score lower, but there is also more variation in the 2008 performance in the diagnostic test.

The difference between the 1998 and 2008 performance for the technology mathematics students is also significant. In 1998, the mean score for these students was $22.7(\mathrm{SD}=6.47)$ and in 2008 , the mean diagnostics score was $20.4(\mathrm{SD}=7.01)$ with a difference of 2.3. There was a statistically significant difference between these means $(t(606)=4.17, p<0.001)$. Again, the standard deviations for these groups show more variance in the performance of the 2008 cohort. The higher percentage of non-standard students in both groups in 2008 may explain this variation in performance within both groups.

In 2007, the technology mathematics students achieved a mean score of 21.95, the highest since 1999. A higher percentage (38\%) of students in this group had Leaving Certificate higher level mathematics this particular year which may account for this peak in performance. For the first 8 years of data, the science mathematics groups outperformed the technology mathematics groups, but this is not the case for the last 3 years $(2006,2007$ and 2008). It is unclear why this is the case as a higher percentage of students in the science mathematics groups had higher level Leaving Certificate 


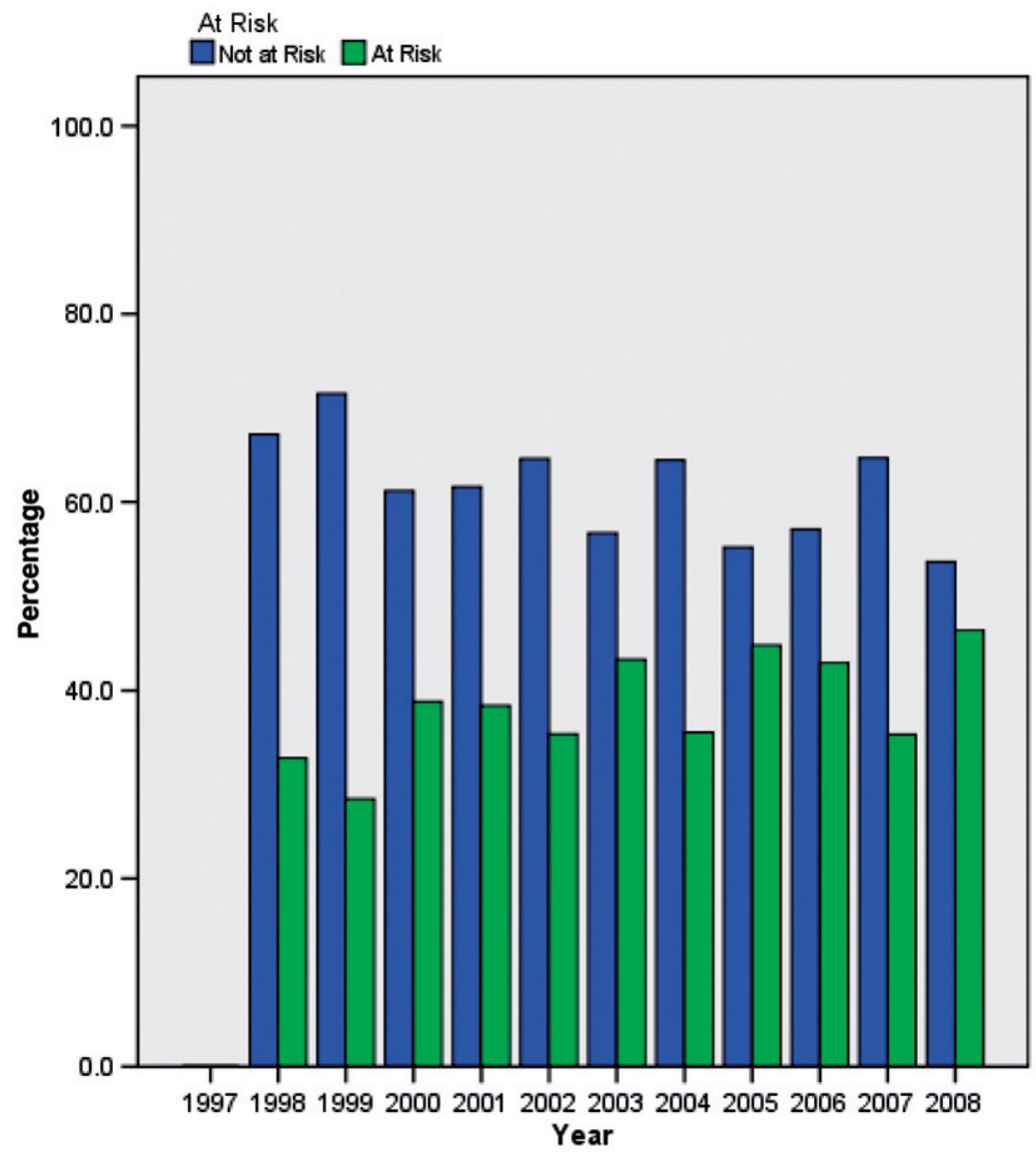

Figure 3. Number of at-risk students in technology mathematics.

mathematics on entry to these courses than those in the technology mathematics groups.

\subsubsection{Leaving Certificate mathematics levels}

Figure 5 illustrates the mean diagnostic test scores of students with higher level Leaving Certificate mathematics, ordinary level Leaving Certificate mathematics and those of non-standard students.

For the higher level students, the mean diagnostic score is consistently above 20 but never above the 30 mark which is worrying considering 35 out of the 40 questions on the test are pitched at a lower level (i.e. Leaving Certificate ordinary level or below). There has been a decline in the mean score of this cohort between 1998 $(M=28.5, \mathrm{SD}=4.85)$ and $2008(M=26.3, \mathrm{SD}=5.38)$. The difference between these means is statistically significant $(t(424)=4.42, p<0.001)$ mostly because of the large sample size.

The mean score for students with ordinary level Leaving Certificate mathematics, since 1998, has consistently been below 20 out of 40 . This is of concern since the minimum entry requirements for science and technology mathematics is an ordinary 


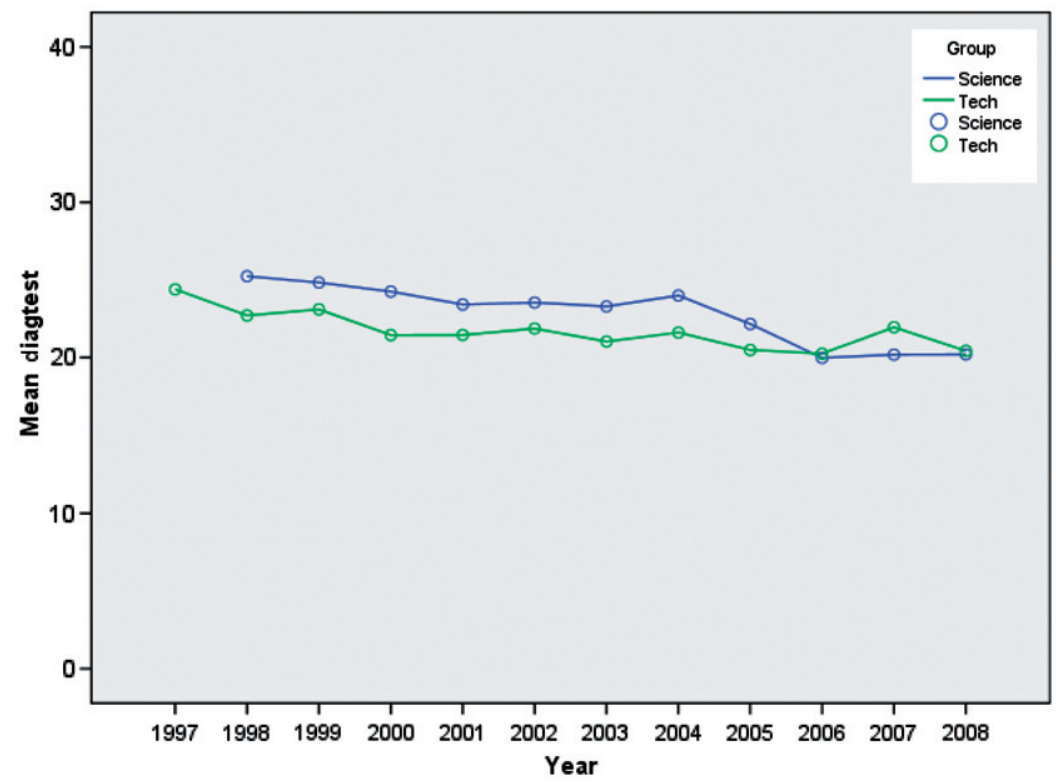

Figure 4. Mean diagnostic score for technology mathematics and science mathematics students, 1998-2008.

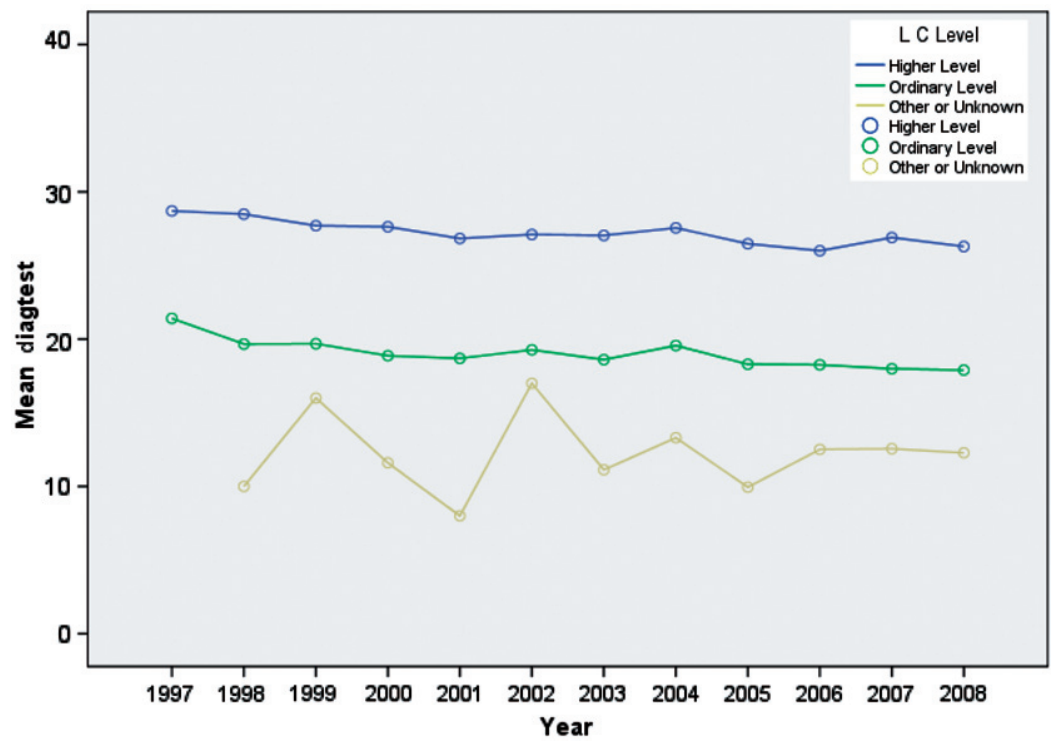

Figure 5. Mean diagnostic test scores by Leaving Certificate level.

level Leaving Certificate B3 and C3, respectively, and over half of the students in the database $(54.2 \%)$ have ordinary level Leaving Certificate mathematics (Figure 6).

Furthermore, there has been a decline in the mathematics standards of this cohort as measured by the diagnostic test. The mean diagnostic score in 1998 for a student with ordinary level Leaving Certificate mathematics was $19.7(\mathrm{SD}=4.73)$ 


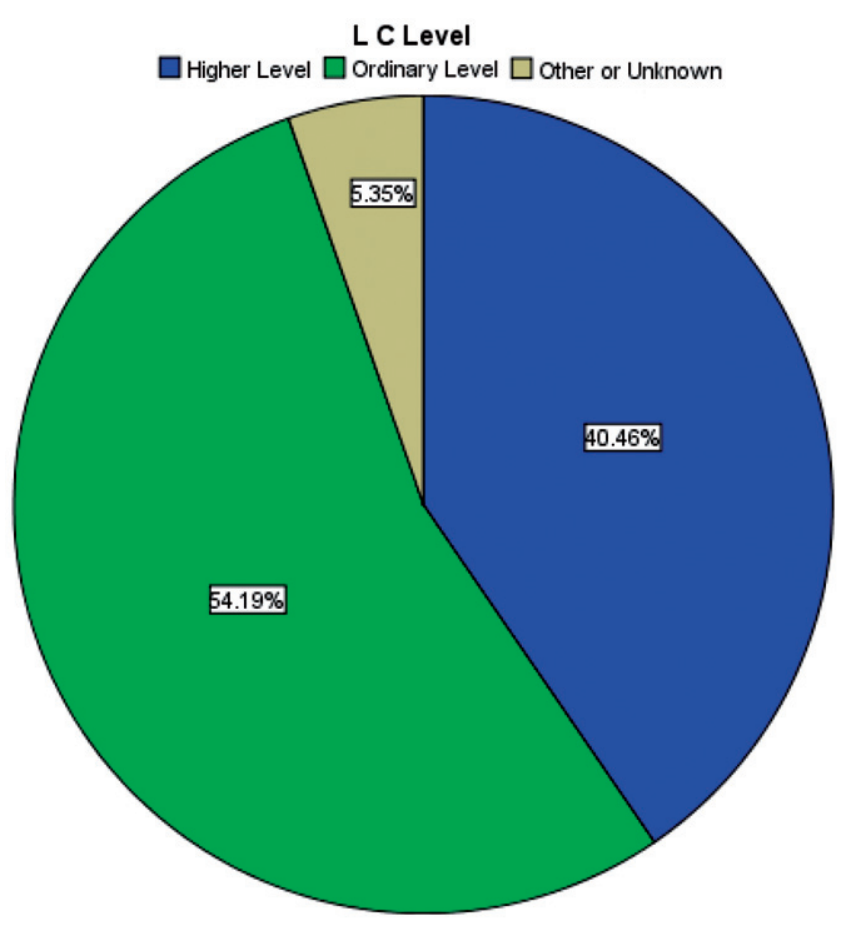

Figure 6. Leaving Certificate levels.

and in 2008 , it had fallen to $17.9(\mathrm{SD}=4.73)$. The difference $(1.8)$ is significant $(t(572)=4.49, p<0.001)$. Coefficients of variations for 1998 and 2008 (24 and 26\%, respectively) indicate slightly more variation in the performance on the test in 2008 .

A total of $5.35 \%$ of the students in the database are non-standard. Either these students have international qualifications other than Leaving Certificate, have no Leaving Certificate (i.e. adult learners) or have neglected to write their Leaving Certificate mathematics grade on their diagnostic test. They represent a small but increasing minority each year. Their mean diagnostic scores are consistently lower than those with Leaving Certificate grades in mathematics.

\section{Reactive measures in place}

Responses to the mathematics problem generally focus on remedying deficiencies through diagnostic testing and follow-up support, transition/bridging courses and learner support generally in the form of MLCs and information and communication technologies (ICT) support. As the number of potentially at-risk students attending UL has risen since 1997, so too has the range of support interventions being offered. In this section, the authors detail the nature of supports now in place for third-level students and the participation levels by students.

\subsection{Support tutorials}

Support tutorials are a widely used support mechanism in UL. Over 200 support tutorials are offered in over 20 mathematics modules each year and are also arranged 


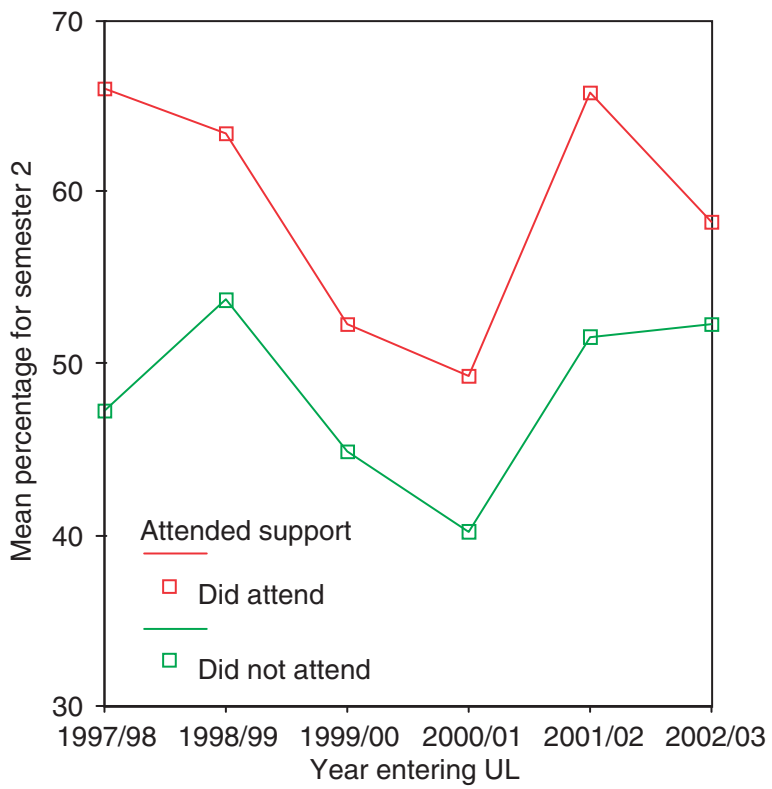

Figure 7. End-of-year mean percentages for at-risk students 1997-2002.

for adult learners in the bigger service mathematics modules. In general, support tutorials are organized to supplement students' current studies. Attendance is not mandatory but is strongly advised for those who score under 20 in their diagnostic tests. All students are welcome, however. Support tutorials run parallel to regular tutorials and so reinforce what is taught in lectures. Tutors focus on specific problems that students have in regular tutorials. Because the support tutorials are student led and they prove to be quite popular and successful. The numbers in attendance are lower in these classes than in regular lectures and tutorials, so students get the opportunity to ask questions, get individual attention and learn in generally a less intimidating atmosphere.

Gill [2] investigated the impact of support tutorials. The results of the end-of-term examinations of those students who are characterized as at risk and participated in the tutorials were compared with those who did not attend to see if there was a difference in examination performance.

Figure 7 displays the end-of-term results for all the at-risk students in the database in the second semester examinations. The students who participated in the support tutorials (two or more support tutorials) scored much better than the students who did not (attended zero or one support tutorial). There is a difference of 18.7\% in 1997/98.

Something like this is very difficult to measure and it is not possible to determine definitively if a student's success can be wholly attributed to the support tutorials they attend. Other factors may contribute to such success such as; peer learning, students getting used to college life, good teaching, etc.

\subsection{Front-end tutorials}

These tutorials are organized over two evenings during the first 2 weeks of the first semester of the academic year in order to help students revise mathematics skills they 
will need for their service mathematics modules. They aim to bring students, particularly adult learners who have been out of formal education for a number of years, up to a satisfactory level of competency in fundamental mathematical skills. In the UL front-end tutorials, these skills include order of operations, fractions, indices, logarithms, manipulating formulae and solving simultaneous equations.

\subsection{MLC: drop-in centre}

The MLC opened in the academic year 2001/02. The MLC administers diagnostic tests and provides study facilities, textbooks, computer-aided learning (CAL) and a fully supervised drop-in facility for 20 hours a week. Very often, students favour one-to-one consultations as a means of learning support as they can ask specific questions on topics they are having trouble with. Revision programmes are organized for students in the week before their examinations. Initially, they were organized to help the MLC deal with the large numbers in attendance seeking help before examinations. These programmes, where a tutor revises the previous year's examination paper in lecture slots (with lecturers' permission), have proven to be increasingly popular with students. Figure 8 displays the attendance figures at the drop-in centre, pre-examination revision programmes and support tutorials (data available for 2002/03 indicates total number of attendances only). The total number of attendances for all three services has more than doubled since its inception in 2001.

\subsection{Head Start Maths}

'Head Start Maths' is an initiative created for adult learners returning to third-level mathematics education. It consists of a 1-week mathematics intensive course which is designed to revise essential mathematics skills and these students may not have studied for a significant period of time and will need for successful completion of their third-level mathematics modules. The course, which started in 2007, runs in

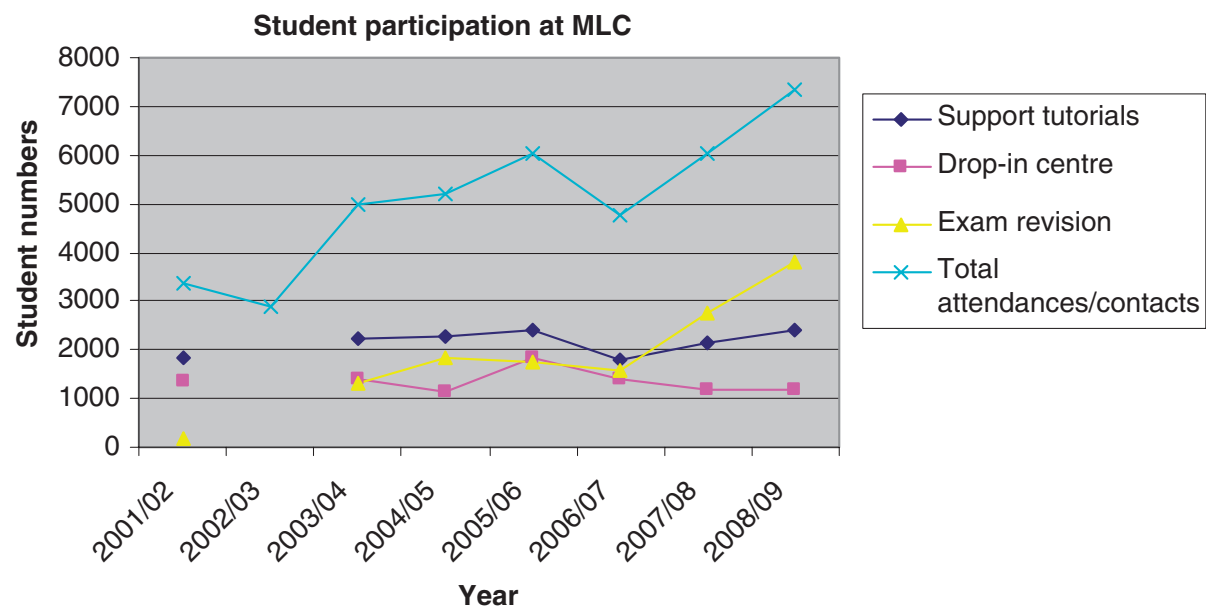

Figure 8. Participation levels at MLC support services. 
August each year before students start their college programmes. Approximately 30 students take part and all materials/notes are provided free of charge. The feedback received from participants was unanimously positive [14].

\subsection{Online support}

The MLC has its own website (www.ul.ie/ mlc) created to extend support time and resources to all UL students who study mathematics. The website provides a number of supports for the main service mathematics modules in the first and second year including access to the past examination papers and sample solutions and a number of useful links such as E-Stats, Maple and HELM (http://helm.lboro.ac.uk/).

\subsection{Fact sheets}

The MLC uses the Loughborough Engineering Maths First-Aid Kit (freely available at www.mathcentre.ac.uk) and has found it very useful. It inspired the MLC to create a new set of one- and two-page information sheets, tailored specifically for UL service mathematics courses. The topics were selected from module syllabi and can be accessed directly from the website.

\section{Conclusion}

This problem of mathematical underpreparedness is a significant problem in the Irish context. Stakeholders in education including the Irish Business and Employers Confederation (IBEC), the Higher Education Authority (HEA), the National Council for Curriculum and Assessment (NCCA) and the Engineers Ireland have been pointing out for a number of years the need to improve standards in mathematics and the sciences, in particular the physical sciences, to support national economic policy, i.e. the development of a smart economy. Mathematics is implicated in this because it underpins these disciplines and the take up of these disciplines. This has been a particular problem in Ireland since the 1990s [3,11,15]. The general consensus is that the standard of mathematics has declined over this period $[2,11]$. Added to this, there has been a decrease in the numbers taking higher level mathematics in the state Leaving Certificate examinations (18.9\% in 2005; $17.1 \%$ in 2007; and $16 \%$ in 2009). In Section 2, Table 2 displayed the evidence of $50 \%$ increase in the number of students participating in the science and technology groups. Therefore, a higher number of students, but with lower mathematics qualifications, are entering third-level education now than was the case 12 years ago. This is translating into significant proportions of underprepared students entering Irish third-level courses, including UL.

In this article, the authors have examined the 'Mathematics Problem' as it manifests itself in the UL. The UL database was initiated in the academic year 1997/98 and has been maintained up to and including the present day for this purpose. Gill [2] carried out preliminary statistical analysis on the period between the years 1997/98 and 2002/03; however, the authors revisited the database to estimate current levels of mathematical underpreparedness as measured by the UL diagnostic test. The analysis of diagnostic test results over a 12-year period displays the evidence of a decline in the mathematical standard of students entering service mathematics 
courses and numbers of potentially at-risk students within these first-year modules reaching as high as $46 \%$ in 2008 . This mathematics problem and decline in standards at $\mathrm{UL}$ is reflected in participation levels at the MLC. Figure 8 showed how the number of contacts (between drop-in centre visits and attendances at support tutorials) has more than doubled since its inception in 2001.

The analyses in this article contribute to a greater understanding, amplification and localization of the 'Mathematics Problem' at UL which is important in terms of dealing with the problem and developing appropriate support mechanisms. Though the results may not be generalizable, they are portable. The view is that this work will contribute to the improvement in service mathematics teaching and support services on a global scale.

\section{References}

[1] D.N. Hunt and D.A. Lawson, Trends in mathematical competency of A-level students on entry to university, Teach. Math. Appl. 15 (1996), pp. 167-173.

[2] O. Gill, What counts as service mathematics? An investigation into the 'Mathematics Problem' in Ireland, unpublished doctoral thesis, University of Limerick, 2006.

[3] Expert Group on Future Skills Needs, Statement on raising national mathematical achievement, EGFSN, Dublin, 2008. Available at http://www.skillsireland.ie/media/ egfsn090616_statement_on_activity.pdf

[4] National Council for Curriculum and Assessment, Review of mathematics in post-primary education: A discussion paper, Dublin, 2005. Available at http://www.ncca.ie/uploadedfiles/MathsReview/MathsDiscusPaperEng.pdf

[5] A. Smith, Making Mathematics Count: The Report of Professor Adrian Smith's Enquiry into Post-14 Mathematics Education, HMSO, London, 2004.

[6] Organisation for Economic Co-operation and Development, Learning for Tomorrow's World - First Results from PISA 2003, OECD, Paris, 2004.

[7] Engineering Council, Measuring the Mathematics Problem, Engineering Council, London, 2000.

[8] TIMMS, Third international mathematics and science study, 1997. Available at http:// www.ed.gov/inits/Math/timss2pg.html

[9] Institute of Mathematics and its Applications, Mathematics Matters in Engineering, IMA, Southend-on-Sea, 1995.

[10] LMS, IMA and RSS, Tackling the Mathematics Problem, London Mathematical Society, London, 1995.

[11] J. O'Donoghue, An intervention to assist at risk students in service mathematics courses at the University of Limerick: University of Limerick teaching fellowship scheme, University of Limerick, Limerick, 1999.

[12] M. Murphy, An investigation into the mathematical under-preparedness present among third level entrants: The possible contribution of the second level mathematics experience, unpublished M.A. thesis, University of Limerick, Limerick, 2002.

[13] M.D.J. Barry and N.C. Steele, A core curriculum in mathematics for the european engineer: An overview, Int. J. Math. Educ. Sci. Technol. 24 (1993), pp. 223-229.

[14] O. Gill, Head start mathematics - report on a programmme for adult learners of mathematics returning to higher education, CETL-MSOR Conference 2008 (Continuing Excellence in the Teaching \& Learning of Maths, Stats \& OR), Lancaster University, Lancaster, 2008.

[15] Government of Ireland, Building Ireland's Smart Economy: A Framework for Sustainable Economic Renewal, The Stationery Office, Dublin, Ireland, 2008. 
Appendix 1. Sample of UL diagnostic test

12. Express 0.01234 in Scientific Notation.

Ans Don't know

13. Divide 30 in the ratio $3: 2$

Ans $\square$ Don't know

\section{ALGEBRA 014-021}

14. Solve for $h: V=\pi r^{2} h$

Ans $\square$ Don't know

15. Evaluate $\mathrm{ab}+2 \mathrm{bc}-3 \mathrm{ac}$ when $a=3, b=-2$ and $c=4$.
Ans $\square$ Don't know

16. Solve the equation: $3(x+2)-24=0$

Ans $\square$ Don't know

17. Solve for $x: x^{2}+x-6=0$

Ans $\square$ Don't know

18. Solve the set of equations:

$$
\begin{aligned}
& 2 x+y=7 \\
& x+2 y=5
\end{aligned}
$$

Ans $\square$ Don't know

19. Write out $(x+3 y)(a-2 b)$ in an equivalent form without brackets.

Ans $\square$ Don't know

20. Solve for $x: \quad 3-6 x<21$

Ans $\square$ Don't know

21. Simplify $\frac{1}{x-1}-\frac{2}{x+1}$

Ans $\square$ Don't know 